\title{
Effect of altitude on spirometric parameters and the performance of peak flow meters
}

\author{
A J Pollard, N P Mason, P W Barry, R C Pollard, D J Collier, R S Fraser, \\ M R Miller, J S Milledge
}

\begin{abstract}
Background - Portable peak flow meters are used in clinical practice for measurement of peak expiratory flow (PEF) at many different altitudes throughout the world. Some PEF meters are affected by gas density. This study was undertaken to establish which type of meter is best for use above sea level and to determine changes in spirometric measurements at altitude.

Methods - The variable orifice miniWright peak flow meter was compared with the fixed orifice Micro Medical Microplus turbine microspirometer at sea level and at Everest Base Camp (5300 m). Fifty one members of the 1994 British Mount Everest Medical Expedition were studied (age range, 19-55).
\end{abstract}

Results - Mean forced vital capacity (FVC) fell by $5 \%$ and PEF rose by $25 \cdot 5 \%$. However, PEF recorded with the mini-Wright peak flow meter underestimated PEF by $31 \%$, giving readings $6.6 \%$ below sea level values. FVC was lowest in the mornings and did not improve significantly with acclimatisation. Lower PEF values were observed on morning readings and were associated with higher acute mountain sickness scores, although the latter may reflect decreased effort in those with acute mountain sickness. There was no change in forced expiratory volume in one second $\left(F E V_{1}\right)$ at altitude when measured with the turbine microspirometer.

Conclusions - The cause of the fall in FVC at $5300 \mathrm{~m}$ is unknown but may be attributed to changes in lung blood volume, interstitial lung oedema, or early airways closure. Variable orifice peak flow meters grossly underestimate PEF at altitude and fixed orifice devices are therefore preferable where accurate PEF measurements are required above sea level. (Thorax 1996;51:175-178)

Keywords: spirometry, altitude, barometric pressure.

Portable peak flow meters are widely used in clinical practice for measurement of peak expiratory flow (PEF) at many different altitudes throughout the world. At altitude the decrease in air density mechanically causes variable orifice meters, such as the mini-Wright, to underestimate flow. ${ }^{1-4}$ An under-reading of $26 \%$ at a simulated altitude of $5455 \mathrm{~m}$ has been demonstrated in hypobaric chamber ex- periments. ${ }^{3}$ However, fixed orifice spirometers such as the Micro Medical Microplus turbine spirometer have recently been evaluated in a hypobaric chamber and are unaffected by barometric pressure. ${ }^{4}$

In the same way that decreased air density causes variable orifice meters to under-read, by decreasing resistance to respiratory gas flow $^{5}$ it causes true PEF to rise at altitude. ${ }^{36}$ Forced vital capacity (FVC) falls with ascent to altitude $^{6-9}$ and a decrease of $3 \%$ at $5500 \mathrm{~m}$ simulated altitude has been recorded. ${ }^{6}$

We compared the mini-Wright peak flow meter with the a hand held turbine spirometer to assess the performance of the two meters in a field study at altitude. FVC, PEF, and forced expiratory volume in one second $\left(\mathrm{FEV}_{1}\right)$ were documented using a turbine spirometer, and PEF using the mini-Wright peak flow meter, in a large study of members of the 1994 British Mount Everest Medical Expedition.

\section{Methods}

After obtaining informed consent, spirometric data were collected from 51 members of the 1994 British Mount Everest Medical Expedition (age range 19-55, 36 men) at sea level (barometric pressure $1012 \cdot 1-1015.5 \mathrm{mB}$ ), in the UK (London and Stirling), and within five days of arrival at Everest Base Camp in Nepal (5300 m, barometric pressure $530-547 \mathrm{mB}$ ). Ethical approval was obtained.

Spirometric measurements were made according to the recommendations of the British Thoracic Society for respiratory function tests ${ }^{10}$ with both a variable orifice mini-Wright peak flow meter (Airmed, Clement Clarke International Ltd, UK) and a fixed orifice turbine spirometer (Micro Medical Ltd, Rochester, Kent, UK). Each forced expiration was performed in a large laboratory tent with an experienced observer. The best of three expirations was recorded for each device. Two hundred and five further spirometric measurements were undertaken with the turbine microspirometer at different times during the first six days at base camp.

Using a standardised acute mountain sickness symptom questionnaire ${ }^{11}$ a score was awarded to each subject before the study.

A general linear model was constructed to determine the relationship between the percentage change from sea level in FVC, PEF, or $F E V_{1}$ and the acute mountain sickness score and time of day. Oxygen saturation, measured as part of a separate study, was also included in the model. A further linear model was con- 


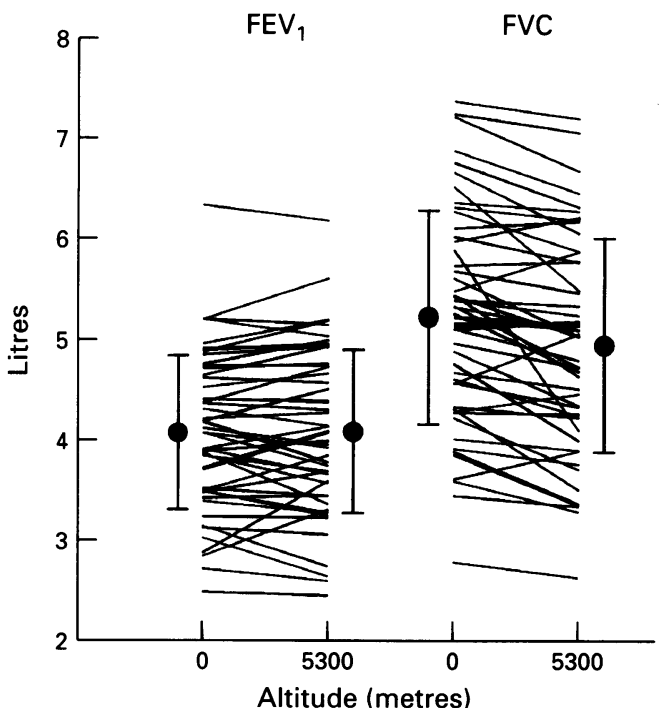

Figure 1 Absolute values, mean and standard deviation $(n=51)$ for forced expiratory volume in one second (FEV) and forced vital capacity (FVC) at sea level and at Everest Base Camp $(5300 \mathrm{~m})$ measured with a turbine spirometer showing no significant change in FEV, and a mean fall in $F V C$ of $5.2 \%$ at $5300 \mathrm{~m}(p<0 \cdot 0001)$.

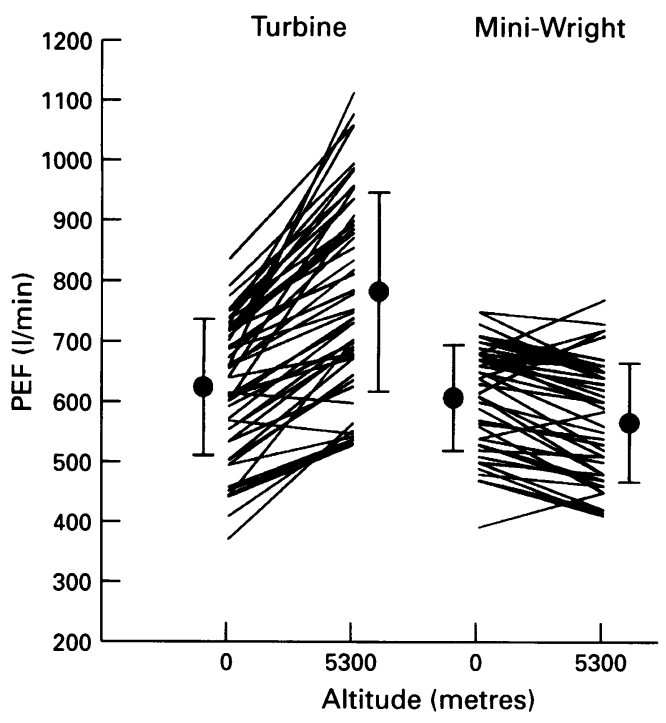

Figure 2 Absolute values, mean and standard deviation for peak flow at sea level and at Everest Base Camp $(5300 \mathrm{~m})$ measured with a turbine spirometer $(n=51)$ showing a mean rise of $25.5 \%(p<0.0001)$ and a miniWright peak flow meter $(n=48)$ showing a $6.6 \%$ fall at $5300 \mathrm{~m}$ below sea level values $(p<0.0001)$.

ings, $95 \%$ CI 0.9 to $5 \cdot 7, \mathrm{p}<0 \cdot 01$ ). FVC was also significantly related to the time of day, with a lower FVC being recorded in the morning $(\mathrm{p}<0.01)$, but was not related to acute mountain sickness score.

The second linear model, constructed to determine the effect of length of stay at base camp (and therefore acclimatisation) on FVC, showed no statistically significant improvement in FVC with time at base camp in 14 subjects from whom data were available, although there was a trend towards sea level values.

At sea level the mean FVC was $5 \cdot 2$ litres (range $2 \cdot 75-7 \cdot 36)$ and the mean PEF using the turbine spirometer was $629 \mathrm{l} / \mathrm{min}$ (range $369-838$ ) and $607 \mathrm{l} / \mathrm{min}$ (range 390-750) with the miniWright peak flow meter. The mean $\mathrm{FEV}_{1}$ was $4 \cdot 1$ litres (range $2 \cdot 46-6 \cdot 32$ ). The differences between the values at sea level and high altitude are summarised in figs 1 and 2 .

Using the turbine spirometer $(n=51)$ FVC fell by a mean of $5 \cdot 2 \%$ ( $95 \%$ confidence interval (CI) -3.3 to $-7 \cdot 2 ; \mathrm{p}<0.0001$ ) at Everest Base Camp compared with sea level, PEF rose by $25.5 \%(21.5$ to $29.5 ; \mathrm{p}<0.0001)$ at $5300 \mathrm{~m}$, and there was no significant change in $\mathrm{FEV}_{1}$ ( $95 \% \mathrm{CI}-1.9$ to $2 \cdot 1 \%$ change). In 48 subjects PEF was also measured with the mini-Wright peak flow meter and fell by $6.6 \%$ below sea level values $(-4 \cdot 2$ to $-9 \cdot 1, \mathrm{p}<0.0001)$. The turbine spirometer gave readings which were a mean (SD) of 22 (34) 1/min higher than the mini-Wright peak flow meter at sea level, rising to a mean difference of 216 (81) $1 / \mathrm{min}$ at $5300 \mathrm{~m}(\mathrm{p}<0.0001)$. There were no significant sex differences in the spirometric data.

Analysis of variance from the general linear model revealed a significant correlation between PEF, acute mountain sickness score and the time of day, with lower PEF being associated with a higher acute mountain sickness score (coefficient $-0.7346, \mathrm{p}<0.05$ ) and morning readings $(3 \cdot 3 \%$ lower than afternoon read-

\section{Discussion}

Our data show a $5 \%$ fall in FVC with ascent to $5300 \mathrm{~m}$ as has been observed by others. ${ }^{6-912}$ Some authors have found that the FVC returns to normal after a period at altitude of seven days, ${ }^{78}$ but this was not confirmed by Ulvedal et $a l^{6}$ after a similar seven days of acclimatisation. We noted a trend towards sea level with time at base camp in a limited number of subjects, but this was not statistically significant.

Several different explanations have been proposed for this fall in FVC. An increase in pulmonary blood volume would reduce the FVC but, in a short exposure to hypoxia, Doyle et $a l^{13}$ found no change in pulmonary blood volume. Our finding of lower values for FVC in the morning probably reflects accumulation of fluid in the supine position overnight, but the measurements were of a similar order to the fluctuations observed by others in healthy subjects at sea level. ${ }^{14}$ Both oedema and an increased lung blood volume might return to normal with a corresponding return to sea level values of FVC after acclimatisation, as observed by others, ${ }^{78}$ although we did not find this. Welsh $e t a l^{15}$ on Operation Everest II performed spirometric studies during a 40 day hypobaric chamber experiment and found a progressive 
fall in FVC which only resolved slowly (over 48 hours) after descent which they also attributed to increased pulmonary blood volume and oedema. Rahn and Hammond ${ }^{7}$ suggested that expansion in intra-abdominal gases might compress the diaphragm and cause a fall in FVC but this was later ruled out by Ulvedal $e t$ $a l .{ }^{6}$ Oxygen absorption from the lung accounts for about $1.6 \%$ of the $7 \cdot 6 \%$ fall in FVC at $10000 \mathrm{~m} .{ }^{6}$ Interstitial or intra-alveolar oedema may be the cause of the fall in FVC at altitude.

In long distance runners a fall in FVC is accompanied by an equivalent rise in residual volume thought to be brought about by early closure of the small airways, possibly due to an increase in extravascular lung water. ${ }^{1617}$ Early closure of the airways might account for the fall in FVC at altitude. If this is so there should be an equivalent rise in residual volume and no change in total lung capacity. Tenney $e t a l^{8}$ found that, on the first day on Mount Evans in Colorado, total lung volume was increased in four subjects due to a rise in residual volume greater than the fall in FVC. However, on the third day FVC fell further and total lung capacity dropped below sea level values. Thereafter there was no clear pattern in lung volume changes.

Fixed orifice spirometers such as the Micro Medical Microplus turbine spirometer have recently been evaluated in a hypobaric chamber and were found to be unaffected by barometric pressure. ${ }^{4}$ Our data, using this device, confirm the finding that PEF rises by $25.5 \%$ at $5300 \mathrm{~m}$, with barometric pressure about half that at sea level. It has long been recognised that decreasing gas density decreases resistance to respiratory gas flow ${ }^{5}$ and this large field study confirms the finding in hypobaric chamber studies that true PEF rises at altitude. ${ }^{346}$

Variable orifice devices such as the miniWright peak flow meter ${ }^{18}$ provide repeatable but non-linear responses at sea level, overreading in the middle of the range ${ }^{19}$ At altitude, however, the decrease in air density mechanically causes the mini-Wright to underestimate flow. ${ }^{1-3}$ Our data confirm a $6.6 \%$ fall in PEF measured with the mini-Wright meter representing an underestimate of $31 \%$. This is similar to the under-reading of $26 \%$ at a simulated altitude of $5455 \mathrm{~m}$ demonstrated in hypobaric chamber experiments. ${ }^{3}$ Thomas et $a \beta$ showed that the underestimation of the mini-Wright meter could be corrected by adding $6.6 \%$ per $100 \mathrm{mmHg}$. This is supported by our data where a correction factor of $6.5 \%$ applies.

The effect of humidity and temperature on the measurements of PEF with either device is uncertain. However, Pedersen et al, ${ }^{4}$ using the Micro Medical spirometer, could not detect any change in PEF from dry to fully saturated air at $37^{\circ} \mathrm{C}$ (but they predicted that there would be a $1.2 \%$ fall). The Micro Medical spirometer has also been tested after three weeks at $-4^{\circ} \mathrm{C}$ when an under-reading of only $1 \%$ was found compared with measurements at the same flow at $25^{\circ} \mathrm{C}$ ( $M$ R Miller, personal communication). Indeed, these observations are not surprising as the temperature at the turbine is relatively unaffected by ambient temperature. At $5^{\circ} \mathrm{C}$ ambient temperature the expired air temperature measured with a fast thermistor was $30^{\circ} \mathrm{C}$ at the turbine, and at $20^{\circ} \mathrm{C}$ ambient temperature it was $31^{\circ} \mathrm{C}$ (C Lawson, Technical Department, Micro Medical, personal communication).

Two studies have shown a correlation between acute mountain sickness and decreased PEF. Singh et $a l^{20}$ looked at PEF in subjects suffering from acute mountain sickness and found a significant reduction in PEF compared with sea level values which was greatest in those individuals with the most severe symptoms. Stockley et $a l^{12}$ also measured PEF before, during, and after a 21 day Himalayan trek and demonstrated a significant drop in PEF in subjects who were severely affected with acute mountain sickness (above $3100 \mathrm{~m}$ ) but not in individuals with mild symptoms. However, these studies did not take into account the effect of the change in air density, and the effect of density on measurement of resistance/airflow at altitude. Our data support their finding of a significant association between lower PEF and higher acute mountain sickness scores. However, we suspect that expiratory effort may be decreased in those symptomatic with acute mountain sickness.

$\mathrm{FEV}_{1}$ was unchanged at $5300 \mathrm{~m}$ compared with sea level values in our study. This reflects the opposing forces of the higher early flow at high altitude in the face of a reduced vital capacity and is supported by previous observations. ${ }^{15}$ The $\mathrm{FEV}_{1} / \mathrm{FVC}$ ratio is therefore increased at altitude as the FVC falls.

Portable peak flow meters are used in clinical practice for measurement of PEF at many different altitudes. Although there is considerable experience of variable orifice devices at sea level, their inaccuracies in mid-flow ranges have only recently been appreciated. These devices underestimate PEF at altitude and we would therefore suggest that fixed orifice devices are preferable. If variable orifice devices are used at altitude, results should be corrected for air density (barometric pressure).

The authors wish to express their gratitude to the 75 member of the 1994 British Mount Everest Medical Expedition who assisted in collecting the data for this study; to Peter Pollard and Isla Martin who performed many of the experiments; to Nick Taub, Department of Epidemiology, University of Leicester, for statistical assistance; to SmithKline Beecham and Zeneca UK for financial support; to Clement Clarke International for supplying hundreds of plastic mouthpieces; to Mr D Quirke of Micro Medical, UK, for supplying the spirometers and for technical advice.

1 Forster P, Parker RW. Peak expiratory flow rate at high altitude. Lancet 1983;ii: 100 .

2 Massen H, Boissinot E, Moiline J. Mesure du debit de pointe et altitude. Cahiers d'Anesthesiologie 1986;34:341-3.

3 Thomas PS, Harding RM, Milledge JS. Peak expiratory flow at altitude. Thorax 1990;45:620-2.

4 Pedersen OF, Miller MR, Sigsgaard T, Tidley M, Harding RM. Portable peak flow meters: physical characteristics influence of temperature, altitude and humidity. Eur Respir influence of temper.

5 Otis AB, Bembower WC. Effect of gas density on resistance to respiratory gas flow in man. $\mathcal{F}$ Appl Physiol 1949;2: to respirat

6 Ulvedal F, Morgan TE, Cutler JR, Welch BE. Ventilatory capacity during prolonged exposure to simulated altitude capacity during prolonged exposure to simulated
without hypoxia. $\mathcal{I}$ Appl Physiol 1963;2:904-8.

7 Rahn H, Hammond D. Vital capacity at reduced barometric pressure. $\mathcal{A}$ Appl Physiol 1952;4:715-25.

8 Tenney SM, Rahn H, Stroud RC, Mithoefer JC. Adaption to high altitude: changes in lung volumes during the first 
seven days at Mt. Evans, Colorado. F Appl Physiol 1953; 5:607-13

9 Shields JL, Hannon JP, Harris CW, Platner WS. Effects of altitude acclimatisation on pulmonary function in women. f Appl Physiol 1968;25:606-9.

10 British Thoracic Society and the Association of Respiratory Technicians and Physiologists. Guidelines for the measurement of respiratory function: topical review. Respir Med 1994;88:165-94.

11 Hackett P. Lake Louise consensus statement on definition of altitude illness. In: Sutton JR, Coates G, Houston CS, eds. Hypoxia and mountain medicine. Burlington: Charles eds. Hypoxia and mountain

12 Stockley RA, Green ID. Birmingham Medical Research Expeditionary Society 1977 Expedition: cardiopulmonary function before, during and after a 21 day Himalayan trek. Postgrad Med f 1979;55:496-500.

13 Doyle JT, Wilson JS, Warren JV. The pulmonary vascular responses to short-term hypoxia in human subjects. Circulation 1952;5:263-71.
14 Cochrane GM, Prieto F, Clark TJH. Intrasubject variability of maximal expiratory flow volume curve. Thorax 1977; 32:171-6.

15 Welsh CH, Wagner PD, Reeves JT, Lynch D, Cink TM, Armstrong J, et al. Operation Everest II: spirometric and radiographic changes in acclimatised humans at simulated high altitudes. Am Rev Respir Dis 1993;147:1239-44.

16 Maron MB, Hamilton LH, Maksud MG. Alterations in pulmonary function consequent to competitive marathon pulmonary function consequent to competi
running. Med Sci Sports 1979;11:244-9.

17 Miles DS, Cox MH, Bomze JP, Gotshall RW. Acute recovery profile of lung volumes and function after running 5 miles. profile of lung volumes and function after r
7 Sports Med Phys Fitness 1991;31:243-8.

18 Wright BM. A miniature Wright peak flow meter. $B M F$ 1978;ii:1627-8.

19 Miller MR, Dickinson SA, Hitchings DJ. The accuracy of portable peak flow meters. Thorax 1992;47:904-9.

20 Singh I, Khanna PK, Srivastava MC, Lal M, Roy SB, Subramanyam CSV. Acute mountain sickness. $N$ Engl $\mathcal{f}$ Med 1969;280:175-85. 